\title{
EFFECT OF RANDOM TEMPERATURE FLUCTUATIONS ON CREEP AND CREEP RUPTURE OF CYLINDRICAL TUBES
}

by

W. N. Huang and R. A. Valentin

BASE TECHNOLOGY

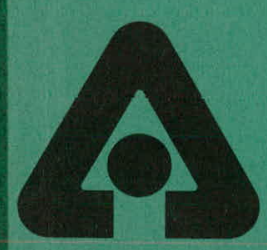

ARGONNE NATIONAL LABORATORY, ARGONNE, ILLINOIS

Prepared for the U.S. ATOMIC ENERGY COMMISSION Division of Reactor Research and Development 


\section{DISCLAIMER}

This report was prepared as an account of work sponsored by an agency of the United States Government. Neither the United States Government nor any agency Thereof, nor any of their employees, makes any warranty, express or implied, or assumes any legal liability or responsibility for the accuracy, completeness, or usefulness of any information, apparatus, product, or process disclosed, or represents that its use would not infringe privately owned rights. Reference herein to any specific commercial product, process, or service by trade name, trademark, manufacturer, or otherwise does not necessarily constitute or imply its endorsement, recommendation, or favoring by the United States Government or any agency thereof. The views and opinions of authors expressed herein do not necessarily state or reflect those of the United States Government or any agency thereof. 


\section{DISCLAIMER}

Portions of this document may be illegible in electronic image products. Images are produced from the best available original document. 
The facilities of Argonne National Laboratory are owned by the United States Government. Under the terms of a contract (W-31-109-Eng-38) between the U. S. Atomic Energy Commission, Argonne Universities Association and The University of Chicago, the University employs the staff and operates the Laboratory in accordance with policies and programs formulated, approved and reviewed by the Association.

\section{MEMBERS OF ARGONNE UNIVERSITIES ASSOCIATION}

The University of Arizona Carnegie-Mellon University Case Western Reserve University The Iniversity of Rhirago Univer sity of Cincinnati Illinois Institute of Tecluvlugy University of Illinois Indiana University Iowa State University The University of Iowa
Kansas State University The University of Kansas Loyola University Marquette Uniworoity Michigan State University The University of Michigan University of Minnesota University of Missouri Northwestern University University of Notre Dame
The Ohio State University Ohio University

The Pennsylvania State University Purduc University

Saint Louis University

Southern Illinols University The University of Texas at Austin Washington University Wayne State University The University of Wisconsin

\section{NOTICE}

This roport wao preparcd as an account of work sponsored

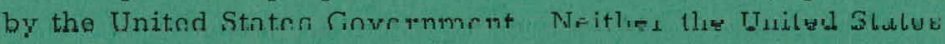
nor the United States Atomic Energy Commission, nor any of their employees, nor any of their contractors, subcontractors, or their employees, makes any warranty, express or implied, or assumes any legal liability or responsibility for the accuracy, completeness or usefulness of any information, apparatus, product or process disclosed, or represents that its use would not infringe privately-owned rights.

Printed in the United States of America Available from

National Technical Information Service

U.S. Department of Commerce

5285 Port Royal Road

Springfield, Virginia 22151

Price: Printed Copy $\$ 4.00$; Microfiche $\$ 1.45$ 
LMFBR Structural Materials and Design Engineering (UC-79h)

\section{ARGONNE NATIONAI LABORATURY \\ 9,700. South Cass Avenue \\ Argonne, Illinois 60439}

\section{EFFECT OF RANDOM TEMPERATURE FLUCTUATIONS \\ ON CREEP AND CREEP RUPTURE OF CYLINDRICAL TUBES}

\section{by}

W. N. Huang* and.R. A. Valentin

Components Technology Division

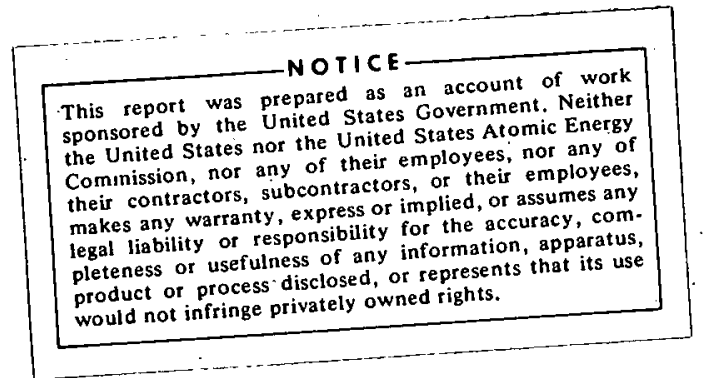

February 1974

*Now with Stone and. Webster-Engineering. Corporation, Boston, Massachusetts 


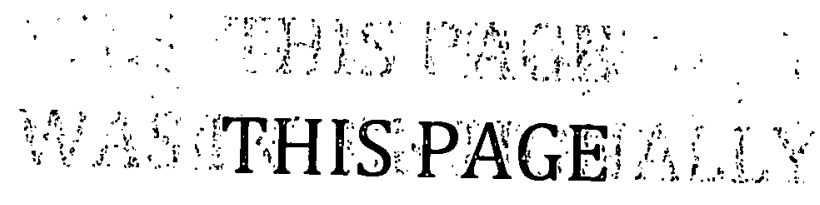
WASINTENTIONALLY LEFT BLANK

$$
3
$$


TABLE OF CONTENTS

Page

NOMENCLATURE ....................... 6

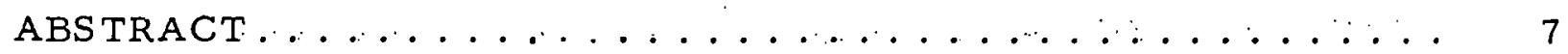

I. INTRODUCTION. .................... 7

II. EFFECT OF RANDOM TEMPERATURE VARIATIONS ON

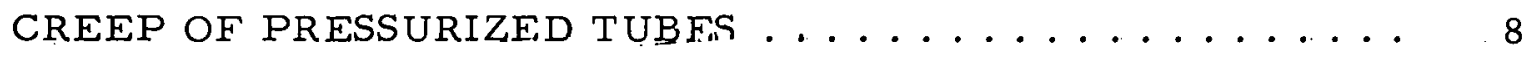

III. RANDOM TEMPERATURE EFFECTS IN CREEP RUPTURE . . . . 14

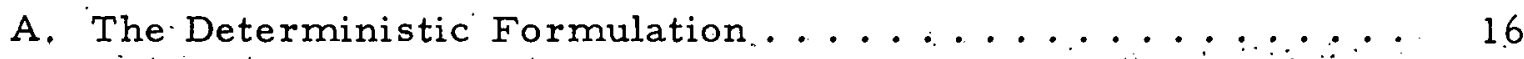

B. The Random-temperature Case .............. 18

IV. EFFECTS OF RANDOM SPATIAL VARIATIONS IN TEMPERATURE ON CREEP PREDICTIONS ............. 21

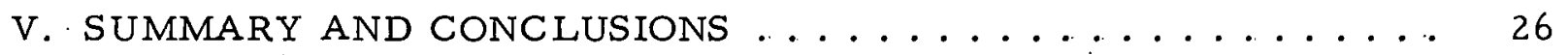

APPENDIX: Deterministic Calculations Using Söderquist's

Creep-damage Model ............... 28

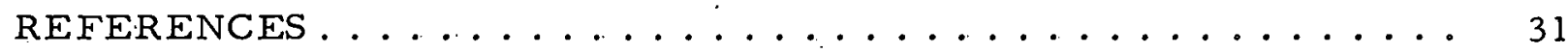




\section{FIGU.RE}

No.

Title

Page

1. Variance of Radius Change as a Function of Dimensionless Correlation Time for Several Values of Dimensionless Temperature Variance....................

\section{LIST OF TABLES}

No.

Title

Page

I. Mean and Standard Deviation of $\Delta \hat{\mathrm{R}} / \Delta \mathrm{R}_{0} \ldots \ldots \ldots \ldots$

II. Expectation Value of $\mathrm{t}_{\mathrm{D}}^{*} / \mathrm{t}_{\mathrm{D}_{0}}^{*} \ldots \ldots \ldots \ldots \ldots \ldots$

III. Expectation Value of $\mathrm{t}_{\mathrm{K}}^{*} / \mathrm{t}_{\mathrm{K} 0}^{*} \ldots \ldots \ldots \ldots \ldots \ldots \ldots \ldots \ldots \ldots \ldots \ldots \ldots \ldots$

IV. Comparison between. Calculated Values of $\mathrm{t}_{\mathrm{K}_{0}}^{*}$ and $\mathrm{t}_{\mathrm{s} 0}^{*} \ldots \ldots \ldots$ 
THIS PAGE

WAS INTENTIONALLY

LEFT BLANK

NOMENCLATURE 
NOMENCLATURE

\begin{tabular}{|c|c|c|c|c|}
\hline a, b & $\begin{array}{l}\text { Inner and outer radii, respectively } \\
\text { Cross-sectional area of rod }\end{array}$ & & $\mathrm{T}_{\mathrm{a}}, \mathrm{T}_{\mathrm{b}}$ & $\begin{array}{l}\text { Inner-and outer-surface tempera- } \\
\text { tures, respectively }\end{array}$ \\
\hline & Fraction of load carrying area & 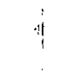 & $\overline{\mathrm{T}}_{\mathrm{a}}, \overline{\mathrm{T}}_{\mathrm{b}}$ & Means of $T_{a}$ and $T_{b}$ \\
\hline$\tilde{A}, \tilde{B}, \tilde{C}$ & Temperature-dependent constants & & $\mathrm{u}$ & Radial creep velocity \\
\hline b & Tube thickness & $\therefore$ & $\mathrm{U}(\mathrm{)}$ & $\begin{array}{l}\text { Unit step function (Heaviside } \\
\text { function) }\end{array}$ \\
\hline C, $v$ & Material constants & I & $\alpha$ & Radius ratio \\
\hline$d_{1}, d_{2}$ & Functions of temperature (Eq. 75 ) & & $\bar{\alpha}, \bar{\beta}$ & Means of $\hat{\alpha}$ and $\hat{\beta}$ \\
\hline & $\begin{array}{l}\text { Flux-dependent parameter (Eq. } 76 \text { ) } \\
\text { Autocovariance of indicated quantity }\end{array}$ & 1 & $\alpha_{R}$ & $\begin{array}{l}\text { Value of } \alpha \text { corresponding to time to } \\
\text { fracture tre }\end{array}$ \\
\hline$d$ & Correlation interval & & $\beta$ & Parameter (Eq. 77b) \\
\hline $\mathrm{D}$ & Damage factor & & 8 & Parameter (Eq. 22) \\
\hline $\operatorname{erf}()$ & Error function & ! & $\delta_{i j}$ & Kronecker delta \\
\hline $\mathrm{E}$ & Modulus of elasticity & & $\varepsilon$ & $\begin{array}{l}\text { Nondimensional creep-viscosity } \\
\text { parameter. }\end{array}$ \\
\hline$f()$ & Probability density function & & & \\
\hline $\mathrm{F}(\mathrm{T})$ & Function of temperature (Eq. 4) & & ${ }^{\mathrm{e}} \mathrm{e}$ & Effective strain \\
\hline $\mathrm{H}$ & Statistical constant (Eq. 70) & & $\varepsilon_{\mathrm{c}}$ & Strain-rate parameter \\
\hline $\mathrm{K}$ & $\begin{array}{l}\text { Temperature-independent constant } \\
\text { (Eq. } 76)\end{array}$ & : & $\begin{array}{l}\dot{\varepsilon}_{c 0} \\
\dot{\varepsilon}_{\mathrm{ij}}\end{array}$ & $\begin{array}{l}\text { Value of } \hat{\tilde{\varepsilon}}_{\mathrm{c}} \text { at } \hat{\mathrm{T}}=\mathrm{T}_{0} \\
\text { Strain-rate tensor }\end{array}$ \\
\hline$\ell$ & Proportionality constant & ? & $n$ & $\begin{array}{l}\text { Argument for autocovariance of } \\
\text { stationary random process }\left(=t_{1}-t_{2}\right) .\end{array}$ \\
\hline $\operatorname{MAX}\{\}$ & $\begin{array}{l}\text { Most probable value of indicated } \\
\text { quantity }\end{array}$ & & $\gamma, \xi$ & Experimentally determined functions \\
\hline $\mathrm{n}$ & Creep exponent & & $\rho, \rho_{\alpha \beta}$ & Correlation coefficients \\
\hline $\mathrm{p}$ & Internal pressure & & $\omega, \lambda$ & Deterministic constants \\
\hline $\mathrm{Q}$ & Constant load & & $\Omega$ & Normalization factor \\
\hline $\mathrm{r}$ & Radial coordinate & & 0 & Integrated neutron flux \\
\hline $\mathrm{R}$ & Tube radius & & $\sigma_{a}$ & Stress acting over undamaged area \\
\hline$R_{i}, b_{i}$ & Initial values of $R$ and $b$ & & $\sigma_{c}$ & Reference stress (chosen as $R_{i} p_{i}^{-1}$ ) \\
\hline$s_{i j}$ & Stress deviator & & $\sigma_{e}$ & Effective stress \\
\hline $\mathrm{t}$ & Time & & $\sigma_{\mathrm{K}}$ & Constant stress (Eq. 42) \\
\hline$t_{K}$ & Time to rupture for which $\sigma=\sigma_{\mathrm{K}}$ & $\vdots$ & $\sigma_{\mathrm{r}}, \sigma_{\theta}, \sigma_{\mathbf{z}}$ & Stresses \\
\hline$t_{R}$ & Time to brittle fracture & & $\sigma_{1_{0}}$ & Initial stress \\
\hline $\begin{array}{c}t^{*} \\
t^{*}\end{array}$ & $\begin{array}{l}\text { Time to rupture } \\
\text { Time to ductile fracture }\end{array}$ & & $\sigma()$ & $\begin{array}{l}\text { Standard deviation of indicated } \\
\text { quantity }\end{array}$ \\
\hline${ }^{\mathrm{t*}}$ & Time to ductile fracture & & 1 & Nondimensional temperature \\
\hline $\mathrm{t}_{\mathrm{H}}^{*}$ & Hoff's ductile-fracture time & : & $<>$ & Expectation value operator \\
\hline $\begin{array}{l}t_{K}^{*} \\
t_{s}^{*}\end{array}$ & $\begin{array}{l}\text { Kachanov's brittle-fracture time } \\
\text { Söderquist's brittle-fracture time }\end{array}$ & & ()$_{0}$ & $\begin{array}{l}\text { Indicates nominal value, i.e., value } \\
\text { when temperature equals mean value }\end{array}$ \\
\hline $\mathrm{T}$ & Temperature & & $\hat{\imath})$ & Designates random quantity \\
\hline$T_{0}$ or. $\bar{T}$ & Mean value of $\hat{T}$ & & & $r$ \\
\hline
\end{tabular}




\title{
EFFECT OF RANDOM TEMPERATURE. FLUCTUATIONS ON CREEP AND CREEP RUPTURE OF CYLINDRICAL TUBES
}

by

\author{
W. N. Huang and R. A. Valentin
}

\begin{abstract}
The design of LMFBR plants requires extensive creep analysis, since many in-core. structures and primary system components operate at elevated.temperatures. In the design process, exact information on the temperature field is often lacking, and this, togethe $r$ with the temperature sensitivity of creep phenomena, leads to uncertainties in derived quantities such as strain and total deformation.

This study considers the qualitative and quantitative implications of random temperature data by deriving expressions: for the expectation value and variance of quantities such as displacement and stress in creep of thin, pressurized tubes. Also, a nondeterministic analog of an existing theory of creep rupture is used to study: the impact of random temperature fluctuations on time to brittle and ductile rupture. Data for stainless. steel are applied in various numerical examples, and the se, together with analytical considerations, are used to formulate qualitative generalizations of importance to the design process.
\end{abstract}

\section{INTRODUCTION}

The vast majority of components designed for service in commercial and research reactors operate in temperature ranges below those for which creep phenomena are significant. As the emphasis in reactor design shifts to more advanced systems, however, operating temperatures increase and a careful consideration of creep becomes a mandatory aspect of design. In particular, with the advent of large.liquid-metal-cooled or high-temperature gas-cooled reactors designed for long service lives, accumulation of appreciable creep strains in core structures and primary piping becomes inevitable. For example, liquid-metal fast breeder reactors. (LMFBR's) such as the FTR and the first demonstration plants will operate at temperatures in excess of $800^{\circ} \mathrm{F}$. This has required: extensive elaboration of the applicable codes and standards so that the creep response of the stainless steels that form the major structural elements can be adequately factored into the design process. 
Since creep rates, creep rupture properties, plastic response, thermal ratcheting, etc., are all temperature-sensitive phenomena, exact knowledge of distributions and variations in temperature is required in most design studies. In early design iterations, however, the exact geometry and operating conditions may not be well defined, and hence, temperature data may be lacking or inexact. Also, even after a design has been made final, the exact operating conditions may vary about nominal values and result in temperature fields that vary in some ill-defined manner. Since creep response is temperaturesensitive, lack of precise knowledge of temperature will be reflected in uncertainties in derived quantities such as displacement rates. For this reason, it is desirable to investigate the effect of random temperature variations on creep response. It is of great potential value to know what derived quantities are affected by'such variations so that given, say, the mean temperature and its standard deviation, the mean and standard deviation of the resulting creep rates can be estimated. Of equal importance is the need to make qualitative statements about such problems. A knowledge of -what quantities a're relatively unaffected by random temperature perturbations immediately clarifies design by uncoupling certain aspects of the design process.

The creep of real materials cannot be treated as a strictly deterministic process, even in the absence of variations in temperature. The random distribution of material imperfections on a microscopic level and macroscopic spatial variations in average material properties produces data scatter in even the most carefully controlled experiments. This aspect of creep will not be treated in this report. : For current literature in this area, see Cozzarelli and Huang; their basic approach in uncoupling the "random temperature problem" from the "random imperfection problem" will be used. Justification for this uncoupling is the relative insensitivity of the creep exponent to temperature, together with its strong dependence on imperfection structure. The converse holds. for the reference strain rate used in the constitutive law.

Section II concentrates on the problem of random temperature in the steady creep of thin circular tubes, since this geometry is probably of greatest concern in both piping and design of core internals. Section III considers the problem of creep rupture in the same geometry. Section IV summarizes the qualitative aspects' of the study and indicates areas in need of further attention.

\section{EFFECT OF RANDOM TEMPERATURE VARIATIONS ON THE CREEP OF PRESSURIZED TUBES}

- In considering the effect of random temperature fluctuations on the stress and deformation state in a pressurized tube at elevated temperature, it is as sumed that the material has entered a stage of secondary creep. Thus, the :general form of the constitutive equations for the materialis

$$
\dot{\varepsilon}_{i j}=\frac{3}{2} \dot{\varepsilon}_{c} \sigma_{c}^{-n_{\sigma} \sigma_{i}^{n-1} s_{i j}}
$$


It is also assumed that Eq. I will hold when the temperature is varying slowly; thus temperature will be considered a random process in time. Since experimental evidence indicates that temperature has only a slight effect on the creep exponent; but a marked effect on the reference creep strain rate, only $\dot{\epsilon}_{c}$ will be treated as a random material parameter. Thus Eq. l is written

$$
\hat{\dot{\varepsilon}}_{i j} \doteqdot \frac{3}{2} \hat{\dot{\varepsilon}}_{c} \sigma_{c}^{-n} \hat{\sigma}_{e}^{n-1} \hat{s}_{i j},
$$

where

$$
\hat{\dot{\varepsilon}}_{c}=F(\hat{T})
$$

with $F(\cdot)$ a known monotonically increasing function.

On physical grounds, it is reasonable to as sume that

$$
F(\hat{\mathrm{T}})=\omega \exp \left(-\lambda \hat{\mathrm{T}}^{-1}\right) \text {. }
$$

However, it is more convenient to approximate the temperature dependence, Eq. 3, by

$$
\hat{\hat{\varepsilon}}_{C}(t)=\dot{\epsilon}_{C 0} \exp [\hat{\tau}(t)]
$$

where

$$
\hat{\tau}(t)=\lambda T_{0}^{-2}\left[\hat{T}(t)-T_{0}\right]
$$

Equations 5 and 6 are a good approximation to the exponential expression in Eq. 4 and result in a more tractable statistical treatment of the problem.

Assuming that $\hat{\mathrm{T}}$. is a stationary normal process with mean $\mathrm{T}_{0}$ implies $\hat{\tau} \cdot$ is stationary normal with zero mean and the first-order density function

$$
f(\tau)=(2 \pi)^{-1 / 2} \sigma_{\tau}^{-1} \exp \left[-\tau^{2}\left(2 \sigma_{\tau}^{2}\right)^{-1}\right] .
$$

Using the definition

$$
\dot{\hat{\epsilon}}(t) \equiv \dot{\epsilon}_{c 0}^{-1} \hat{\hat{\varepsilon}}_{c}(t)=\exp [\hat{\tau}(t)]
$$

and the results of Cozzarelli and Huang, 1 it may be shown that $\hat{\varepsilon}(t)$ is a stationary random process with the first-order density function

$$
f(\varepsilon)=\left[(2 \pi)^{1 / 2} \sigma_{\tau} \varepsilon\right]^{-1} \exp \left[-(\ell n \varepsilon)^{2}\left(2 \sigma_{\tau}^{2}\right)^{-1}\right] U(\varepsilon)
$$

Equation 9 is the density function for the lognormal distribution, and its properties are well known; for example, see Ref. 2 " The major statistical properties of this distribution that will be used in the development to follow are 


$$
\begin{aligned}
& \langle\hat{\varepsilon}\rangle=\exp \left(\sigma_{\tau}^{2} / 2\right)>1 \\
& \sigma_{\varepsilon}^{2}=\exp \left(\sigma_{\tau}^{2}\right)\left[\exp \left(\sigma_{\tau}^{2}\right)-1\right]>\sigma_{\tau}^{2},
\end{aligned}
$$

and

$$
C_{\varepsilon}(\eta)=\exp \left(\sigma_{T}^{2}\right)\left\{\exp \left[C_{T}(\eta)\right]-1\right\}
$$

where $C_{\tau}(\eta)$ is the autocovariance of $\hat{\tau}$, and $\eta=t_{1}-t_{2}$.

Consider a thin cylindrical tube of radius $\hat{R}(t)$ and thickness $\hat{h}(t)$ subjected to a.constant internal pressure p. The various stress components are

$$
\begin{aligned}
& \hat{\sigma}_{\theta}=2 \hat{\sigma}_{z}=p \hat{R} \hat{b}^{-1}, \hat{\sigma}_{r} \equiv 0, \\
& \hat{\sigma}_{e}=\frac{\sqrt{3}}{2} \frac{p \hat{R}}{\hat{b}},
\end{aligned}
$$

and

$$
\hat{s}_{\theta}=-\hat{s}_{\mathbf{r}}=\frac{\hat{\sigma}_{\theta}}{2}, \hat{s}_{\mathbf{z}} \equiv 0
$$

and, from Eq. 2, the strain-rate expressions are

$$
\hat{\hat{\varepsilon}}_{\theta}=-\hat{\hat{\varepsilon}}_{\mathrm{r}}=\hat{\hat{\varepsilon}}_{\mathrm{c}}\left(\frac{\sqrt{3}}{2}\right)^{\mathrm{n}+1}\left(\frac{\hat{\sigma}_{\theta}}{\sigma_{\mathrm{c}}}\right)^{\mathrm{n}} \text { and } \hat{\hat{\varepsilon}}_{\mathrm{z}}=0
$$

Assuming Eq. 2. holds for logarithmic strain,

$$
\hat{\varepsilon}_{\theta}=\ln \frac{\hat{R}(t)}{R_{i}}
$$

and noting that incompressibility implies

$$
R_{i} b_{i}=\hat{R}(t) \hat{b}(t) \text {, }
$$

it follows that

$$
\hat{\sigma}_{\theta}(t)=\frac{R_{i} p}{b_{i}} \exp \left[2 \hat{\varepsilon}_{\theta}(t)\right] .
$$

Hence, from Eq. 16,

$$
\hat{\dot{\varepsilon}}_{\theta}=B \hat{\dot{\varepsilon}}_{c}(t) \exp \left[2 n \hat{\varepsilon}_{\theta}(t)\right] \text {, }
$$


where, for convenience, $\sigma_{C}:=R_{i} p_{i}^{-1}$, and thus $B=(\sqrt{3} / 2)^{n+1}$. The solution to Eq. 20 considered as a differential equation in $\hat{\epsilon}_{\theta}$ is

$$
\hat{\epsilon}_{\theta}(t)=\ln \left[1-2 n B \cdot \int_{0}^{t} \hat{\dot{\epsilon}}_{c}(\xi) \cdot d \xi\right]^{-1 / 2 n} .
$$

Let

$$
\hat{R}(t)=R_{i}+\delta \Delta \hat{R}(t)
$$

where $\delta$ is defined so that $\delta \Delta \hat{\mathrm{R}} \ll \mathrm{R}_{\mathbf{i}}$ : Thus, to a first approximation,

$$
\left[\frac{R(t)}{R_{i}}\right]^{-2 n}: 1-2 n \delta \Delta \hat{R}(t) R_{i}^{-1}
$$

From this approximation and Eqs. 17 and 21 , it follows that

$$
\delta \Delta \hat{R}(t)=B R_{i} \dot{\varepsilon} c 0 \int_{0}^{t} \hat{\varepsilon}(\xi) \cdot d \xi
$$

Defining the nominal value $\Delta R_{0}(t)$ as that resulting when $\hat{T}=. T_{0}$, it also follows that $\delta \Delta R_{0}(t)=B R_{i} \dot{\varepsilon}_{c o} t ;$ thus,

$$
\frac{\Delta \hat{R}(t)}{\Delta R_{0}(t)}=\frac{1}{t} \int_{0}^{t} \hat{\varepsilon}(\xi) d \xi
$$

In the special case when $\hat{\varepsilon}(\xi)$ is assumed to be a random variable $\hat{\varepsilon}$, Eq. 24 gives $\Delta \hat{R}(t) / \Delta R_{0}(t)=\hat{\varepsilon}$, and the density function of $\Delta \hat{R}(t) / \Delta R_{0}(t)$ becomes the lognormal density function $f(\epsilon)$. In the general case of $\hat{\varepsilon}(\xi)$, determination of the density function is extremely complicated and shall not be attempted here; however, its mean and variance will be determined as follows.

From Eqs. 10 and 24 and the stationarity of $\hat{\varepsilon}(\xi)$, we obtain the mean

$$
\left\langle\frac{\Delta \hat{R}(t)}{\Delta R_{0}(t)}\right\rangle=\exp \left(\frac{\sigma_{T}^{2}}{2}\right)
$$

in which the mean diameter change always exceeds the nominal value based on the mean temperature.

We now examine the second-order statistics of the problem. From Eq. '24, it follows that. . .

$$
\left\langle\frac{\Delta \hat{R}\left(t_{1}\right)}{\Delta R_{0}\left(t_{1}\right)} \frac{\Delta \hat{R}\left(t_{2}\right)}{\Delta R_{0}\left(t_{2}\right)}\right\rangle=\frac{1}{t_{1} t_{2}} \int_{0}^{t_{1}} \int_{0}^{t_{2}}\left\langle\hat{\varepsilon}\left(\xi_{1}\right) \hat{\varepsilon}\left(\xi_{2}\right)\right\rangle d \xi_{1} d \xi_{2}
$$


where

$$
\left\langle\hat{\varepsilon}\left(\xi_{1}\right) \hat{\varepsilon}\left(\xi_{2}\right)\right\rangle=\exp \left(\sigma_{\tau}^{2}\right) \exp \left[C_{\tau}(\eta)\right], \quad \eta=\xi_{1}-\xi_{2} .
$$

It is physically reasonable to choose the autocovariance

$$
C_{\tau}(\eta)=\sigma_{\tau}^{2} \exp \left(-\frac{|\eta|}{d}\right)
$$

where $d$ is some assigned correlation interval modeling the qualitative as pects of the characteristic times associated with the assumed temperature field. In the present case, $d$ will be considered a parameter to define the time scale. From Eq. 28 , it can be shown that $\hat{\hat{\varepsilon}}_{c}(t)$, and thus $\hat{\varepsilon}(t)$, a re ergodic in the mean. From Eqs. 26-28, the autocorrelation function is

$$
\left\langle\frac{\Delta \hat{R}\left(t_{1}\right)}{\Delta R_{0}\left(t_{1}\right)} \frac{\Delta \hat{R}\left(t_{2}\right)}{\Delta R_{0}\left(t_{2}\right)}\right\rangle=\frac{\exp \left(\sigma_{T}^{2}\right)}{t_{1} t_{2}} \int_{0}^{t_{1}} \int_{0}^{t_{2}} \exp \left[\sigma_{T}^{2} \exp \left(-\frac{|\eta|}{d}\right)\right] d \xi_{1} d \xi_{2} .
$$

From Eq. 24, the variance at time $t$ is given by

$$
\sigma_{\Delta \mathrm{R} / \Delta \mathrm{R}_{0}}^{2}=\frac{1}{\mathrm{t}} \int_{0}^{2 \mathrm{t}}\left(1-\frac{\eta}{2 \mathrm{t}}\right) \mathrm{C}_{\epsilon}(\eta) \mathrm{d} \eta
$$

where

$$
C_{\epsilon}(\eta)=\exp \left(\sigma_{\tau}^{2}\right)\left\{\exp \left[\sigma_{\tau}^{2} \exp \left(-\frac{|\eta|}{d}\right)\right]-1\right\}
$$

The integral in Eq. 30 is evaluated to give

$$
\sigma_{\Delta \mathrm{R} / \Delta \mathrm{R}_{0}}^{2} \sigma_{\varepsilon}^{-2}=\left[\exp \left(\sigma_{\tau}^{2}\right)-1\right]^{-1} \frac{\mathrm{d}}{\mathrm{t}} \sum_{\mathrm{k}=1}^{\infty} \frac{\sigma_{T}^{2 \mathrm{k}}}{\mathrm{k}(\mathrm{k} !)}\left\{1-\frac{\mathrm{d}}{2 \mathrm{kt}}\left[1-\exp \left(-\frac{2 \mathrm{kt}}{\mathrm{d}}\right)\right]\right\},
$$

which is used to develop the limits

$$
\lim _{d / t \rightarrow 0}\left(\frac{\sigma_{\Delta R}^{2} / \Delta R_{0}}{\sigma_{\epsilon}^{2}}\right)=0, \lim _{d / t \rightarrow \infty}\left(\frac{\sigma_{\Delta R}^{2} / \Delta R_{0}}{\sigma_{\varepsilon}^{2}}\right)=1
$$

Although the expression for the mean diameter change, Eq. 25, is timeindependent, the variance, Eq. 31 ; is an explicit function of time; thus $\Delta \hat{R} / \Delta R_{0}$ is only stationary in the mean. Figure l shows the variance ratio, Eq. 31 , plotted as a function of $\mathrm{d} / \mathrm{t}$ for several values of $\sigma_{\tau}$. The diameter change is clearly sensitive to perturbations in the temperature field. 


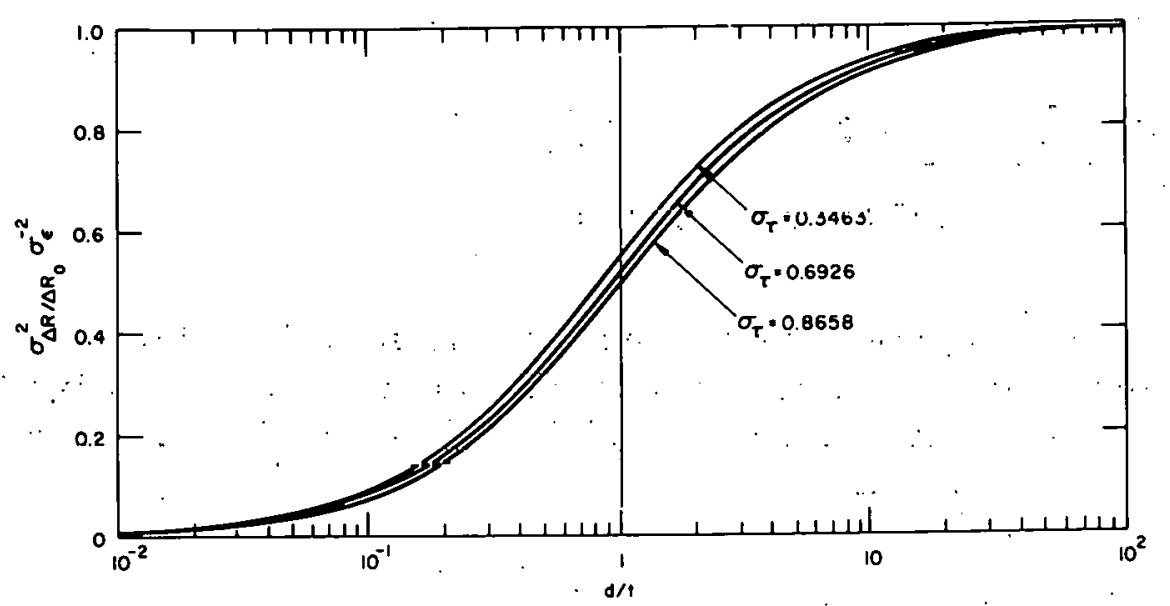

Fig. 1. Variance of Radius Change as a Function of Dimensionless Correlation Time for Several Values of Dimensionless Temperature Variance

As a specific example, consider a Type 304 stainless steel tube operating at $\mathrm{T}_{0}=1560^{\circ} \mathrm{R}$. Using data from Ref. 3, assuming $\sigma_{\mathrm{T}}=10^{\circ}, 20^{\circ}$, and $25^{\circ}$, and taking $\mathrm{d} / \mathrm{t}=1$, evaluation of Eqs. $10,11,25$, and 3.1 yields the results given in Table $I$.

TABLE I. Mean and Standard Deviation of $\Delta \hat{R} / \Delta R_{0}$

\begin{tabular}{ccccc}
\hline$\sigma$ & $\sigma_{\tau}$ & $\Delta \hat{\mathrm{R}} / \Delta \mathrm{R}_{0}$ & $\sigma_{\epsilon}$ & $\sigma_{\Delta \mathrm{R}} / \Delta \mathrm{R}_{0}$ \\
\hline 10 & 0.3463 & 1.0618 & 0.3792 & 0.2740 \\
20 & 0.6926 & 1.2712 & 0.9978 & 0.7210 \\
25 & 0.8658 & 1.4550 & 1.5378 & 1.1110 \\
\hline
\end{tabular}

In addition to the fact that $\left\langle\Delta \hat{R} / \Delta R_{0}\right\rangle>i$, the variance in the random. temperature is not related in any simple manner with the resulting variance in the radius change, other than an apparent monotonic behavior showing that increases in $\sigma_{\tau}$ will increase $\sigma_{\Delta R} / \Delta R_{0}$.

To determine the stress response of the cylinder, note that

$$
\hat{\sigma}_{\dot{\theta}}(t)=\frac{\dot{p}[\hat{R}(t)]^{2}}{R_{i} b_{i}}
$$

and, since Eqs. 17 and 21 imply

$$
\hat{R}(t)=R_{i}\left[1-2 n B \int_{0}^{t} \hat{\varepsilon}_{c}(\xi) d \xi\right]^{-1 / 2 n}
$$

it follows that

$$
\hat{\sigma}_{\theta}(t)=\frac{p R_{i}}{b_{i}}\left[1-2 n B \dot{\varepsilon}_{c 0} \int_{0}^{t} \hat{\varepsilon}(\xi) d \xi\right]^{-1 / n} .
$$


Therefore,

$$
\frac{\hat{\sigma}_{\theta}(t)}{\sigma_{\theta_{0}}(t)}=\left[\frac{1-2 n B \dot{\varepsilon}_{c o t}}{1-2 n B \dot{\varepsilon}_{c 0} \int_{0}^{t} \hat{\varepsilon}(\xi) d \xi}\right]^{1 / n} \text {. }
$$

To determine the density function, mean, and variance of $\sigma_{\theta}(t) / \sigma_{\theta_{0}}(t)$ either explicitly or by numerical methods would be a prohibitive task. It is true, however, that when Eq. 28 is valid, $\hat{\varepsilon}(t)$ is ergodic in the mean. Thus for a sufficiently long time,

$$
\frac{1}{t} \int_{0}^{t} \hat{\varepsilon}(\xi) d \xi \cong E\{\hat{\varepsilon}(\xi)\}=\exp \left(\sigma_{\tau}^{2} / 2\right)
$$

and

$$
\frac{\hat{\sigma}_{\theta}(t)}{\sigma_{\dot{\theta}_{0}}(t)} \cong\left[\frac{1-2 n B \dot{\epsilon}_{c 0} t}{1-2 n B \dot{\varepsilon}_{c 0} t \exp \left(\sigma_{\tau}^{2} / 2\right)}\right]^{1 / n}
$$

Fortimes of the order of $\mathrm{t}=10^{5} \mathrm{hr}$ (for Type 304 stainless steel),

$$
\text { and } \left.\quad \begin{array}{l}
2 n B \dot{\varepsilon} \cot \ll 1 \\
\\
\quad \frac{\hat{\sigma}_{\theta}(t)}{\sigma_{\theta_{0}}(t)} \cong 1
\end{array}\right\}
$$

implying that the stress state is almost deterministic.*

\section{RANDOM TEMPERATURE EFFECTS IN CREEP RUPTURE}

To assess the effects of uncertainty in temperature on the ability to predict creep rupture, it is necessary to work within the framework provided by a well-defined theory. Since an extensive literature on random temperature considerations in this area does not exist, it is first necessary to study the qualitative aspects of the problem. For this purpose, the re is no need to have a detailed model or to incorporate comprehensive materials data. Such refinement can follow after the general nature of the problem has been studied, and after there is some indication that the effects of random temperature are of sufficient interest to justify production of a design-oriented formulation.

*It is not true that as $t \rightarrow \infty, \hat{\sigma}_{\theta}(t) / \sigma_{\theta 0}(t) \rightarrow 1$. Rather, Eq. 37 holds for physically realistic values of $t$ (e.g., $10^{5} \mathrm{hr}$ ). 
Thus, in the development that follows, emphasis is placed on relatively elementary phenomenological theories exhibiting the basic aspects of ductile and brittle creep rupture.

For many structural materials, the data on creep rupture have the same general form. On a log-log plot of initial stress $\sigma_{1_{0}}$ versus time to failure $t^{*}$, there are two distinctive regions. For small values of $t^{*}$ and large stresses, the rupture is ductile, and the curves have a relatively shallow slope with increasing t*. For low stress and long times, the rupture is brittle and the slope much greater. The ductile part of the curve can be trcated readily, using the phenomenological theory of Hoff. ${ }^{4}$ By assuming a power law for secondary creep and working with logarithmic strain, Hoff showed. that the time to rupture was given by

$$
t_{H}^{*}=\frac{1}{n}\left(\frac{\sigma_{c}}{\sigma_{1_{0}}}\right)^{n}
$$

where $n$ and $\sigma_{c}$ are material constants in the creep law. In this simplified theory, $t_{H}^{*}$ represents the time required. for the original section to reduce to zero area.

To account for the long-term material deterioration, which, in some sense, is the essence of brittle creep rupture, Kachanov ${ }^{5}$ developed a phenomenological cumulative-damage theory. As presented by Odquist, ${ }^{6}$ this theory.. assumes that deterioration is a direct result of tensile stresses. In its one-dimensional formulation, a prismatic rod of cross-sectional area $A$ is subjected to a.constant tensile load $P$. It is assumed that, at any given time, only some fraction of the area $A_{r}$ is able to carry the load; thus a damage factor is defined as

$$
D=\frac{A-A_{r}}{A}
$$

The actual stress on the supporting area $\sigma_{r}$ increases above its nominal value $\sigma=P / A$ as $A_{r}$ decreases. It is assumed that the rate of increase of the damage is

$$
\frac{d D}{d t}=f\left(\sigma_{r}\right)=f\left(\frac{\sigma}{l-D}\right)
$$

with the initial condition $D=0$ at $t=0$. Integration of this equation then yields the time to rupture $t_{R}$ for which $D=1$. If $f$ is of the simple form

$$
f(x)=C x^{\nu}
$$

where $C$ and $\nu$ are material constants, it follows that 


$$
\int_{0}^{1}(1-\dot{D})^{\nu} d D=\frac{1}{1+\nu}=C \int_{0}^{t} \sigma^{\nu} d t
$$

By assuming that the various material constants are determined such that $t_{K}$ corresponds to a time to rupture for which the nominal stress $\sigma=\sigma_{\mathrm{K}}=$ constant, the above criterion may be written

$$
\int_{0}^{t_{R}}\left(\frac{\sigma}{\sigma_{K}}\right)^{\nu} d t=t_{K} .
$$

This is es sentially the form presented by Kachanov ${ }^{5}$ and is equivalent to the linear cumulative creep-damage law given in Refs. 7 and 8 .

In considering the effect of random temperature, emphasis will be placed on use of the criterion given in Eq. 42 or in slight generalizations of this result. The treatment of random temperature effects. in ductile creep rupture will be handled independently of the Hoff theory, since the Kachanov formulation can be suitably modified to describe both ductile and brittle creep rupture.

Before considering the detailed random-temperature case, the possible generalizations of the basic failure criteria should be noted and their implications explored in a deterministic sense. In particular, the multidimensional extension of Eq. 42 will be taken as

$$
\int_{0}^{t \mathrm{R}}\left|\frac{\sigma_{\max }}{\sigma_{\mathrm{K}}}\right|^{\nu} \mathrm{dt}=\mathrm{t}_{\mathrm{K}},
$$

where $\sigma_{\max }$ is the maximum principal stress and is assumed to be tensile. It is possible that the effective stress $\sigma_{e}$ should replace $\sigma_{\max }$ in Eq. 43; however, use of $\sigma_{\max }$ results in a simpler analysis, which is generally in qualitative agreement with experiment.

\section{A. The Deterministic Formulation}

Following Odqvist, 6 the creep rupture problem for a thin pressurized tube may be formulated by introducing the notation

$$
\sigma \theta_{0}=\mathrm{pR}_{\mathrm{i}} \mathrm{b}_{\mathrm{i}}^{-1}, \alpha=\mathrm{RR}_{\mathrm{i}}^{-1},
$$

and using logarithmic strains, to obtain

$$
\varepsilon_{\theta}=\ln \alpha, \quad \dot{\varepsilon}_{\theta}=\dot{\alpha} \alpha^{-1}
$$

Incompressibility then implies

$$
\sigma_{\theta}=\sigma_{\theta_{0}} \alpha^{2}
$$


and, using the creep law in power form with $\sigma_{\theta_{0}}$ as the reference stress,

$$
\dot{\alpha}=\mathrm{B} \dot{\epsilon}_{\mathrm{C} 0} \alpha^{2 \mathrm{n}+1}
$$

where

$$
B=\left(\frac{\sqrt{3}}{2}\right)^{n+1}
$$

Noting that $\alpha=1$ at $\mathrm{t}=0, \mathrm{Eq} .47$ is integrated to give

$$
1-\alpha^{-2 n}=2 n B \dot{\varepsilon} c o t
$$

For ductile rupture, $\alpha \rightarrow \infty$, and thus the time to ductile failure is given by

$$
\mathrm{t}_{\mathrm{D}_{0}}^{*}=\left(2 \mathrm{nB} \dot{\epsilon}_{\mathrm{co}}\right)^{-1}
$$

To estimate the time to brittle failure $t_{K_{0}}^{*}$, it is first noted that

$$
\sigma_{\max }=\sigma_{\theta}=\sigma_{\theta_{0}} \alpha^{2}
$$

and the integral criteria, Eq. 43, then implies

$$
t_{K}=\int_{0}^{t_{K_{0}}^{*}}\left|\frac{\sigma_{\theta_{0} \alpha^{2}}}{\sigma_{K}}\right|^{\nu} d t=\left(\frac{\sigma_{\theta_{0}}}{\sigma_{K}}\right)^{\nu} \int_{1}^{\alpha_{R}} \alpha^{2 \nu} \frac{d t}{d \alpha} d \alpha
$$

where $\alpha_{R}$ is that value of $\alpha$ corresponding to the time to failure $\mathrm{t}_{\mathrm{K}_{0}}^{*}$.

Computing dt/d $\alpha$ from Eq. 48 and substituting into Eq. 51 gives

$$
t_{K}=\left(\frac{\sigma_{\theta_{0}}}{\sigma_{K}}\right)^{\nu}\left(B \dot{\varepsilon}_{c 0}\right)^{-1} \int_{1}^{\alpha} \alpha^{2 \nu-2 n-1} d \alpha \text {. }
$$

Examination of existing data shows $\nu<n$, and evaluation of the integral in Eq. 52 yields

$$
\alpha_{\mathrm{R}}^{2 n}=\left[1-2(\mathrm{n}-\nu) \cdot B \dot{\varepsilon}_{\mathrm{c}}\left(\frac{\sigma_{K}}{\sigma_{\theta_{0}}}\right)^{\nu} \mathrm{t}_{\mathrm{K}}\right]^{\mathrm{n} /(\mathrm{n}-\nu)} \cdots
$$

Since Eq. 48 implies

$$
1-\alpha_{\mathrm{R}}^{-2 \mathrm{n}}=2 \mathrm{nB} \dot{\epsilon}_{\mathrm{cot}}{\stackrel{*}{K} K_{0}}
$$

this and Eq. 53.give for the time to brittle failure 


$$
t_{K_{0}}^{*}=\left(2 n B \dot{\varepsilon}_{c 0}\right)^{-1}\left\{1-\left[1-2(n-\nu) B \dot{\varepsilon}_{c o}\left(\frac{\sigma_{K}}{\sigma_{\theta_{0}}}\right)^{\nu} t_{K}\right]^{n /(n-\nu)}\right\} .
$$

In the nondeterministic development to follow, the treatment parallels that given above. Consideration was given to the possibility of using a more comprehensive model of the brittle failure mechanism based on the work of Söderquist; 9 however, in the deterministic cases evaluated, the differences proved minor (see appendix). For this reason and for simplicity, Kachanov's formulation was adjudged adequate.

\section{B. The Random-temperature Case}

If the assumptions stated in Sec. II a re applied to the case in which temperature is a random process in $t$, Eq. 47 becomes

$$
\hat{\dot{\alpha}}=B \dot{\epsilon} c_{0} \hat{\epsilon} \hat{\alpha}^{2 n+1},
$$

and, since $\hat{\alpha}=1$ at $t=0$,

$$
1-\hat{\alpha}^{-2 n}=2 n B \dot{\varepsilon} \operatorname{co} \int_{0}^{t} \hat{\varepsilon}(\xi) d \xi
$$

From the properties of the lognormal density function, the expectation value of $\mathrm{Eq} .57$ is

$$
1-\left\langle\hat{\alpha}^{-2 n}\right\rangle=2 n B \dot{\epsilon} \cot \exp \left(\sigma_{\tau}^{2} / 2\right)
$$

and, since ductile failu, re will correspond to $\left\langle\hat{\alpha}^{-2 n}\right\rangle=0$,

$$
t_{D}^{*}=\left[2 n B \dot{\epsilon}_{c o} \exp \left(\sigma_{T}^{2} / 2\right)\right]^{-1} .
$$

Comparison of Eq. 59 with the deterministic result, Eq. 49, yields

$$
\frac{t_{D}^{*}}{t_{D_{0}}^{*}}=\exp \left(-\sigma_{\mathrm{T}}^{2} / 2\right)
$$

\begin{tabular}{|c|c|c|}
\hline$\sigma_{\mathrm{T}},{ }^{\circ} \mathrm{R}$ & $\sigma_{T}$ & $\mathrm{t}_{\mathrm{D}}^{*} / \mathrm{t}_{\mathrm{D}_{0}}^{*}$ \\
\hline 10 & 0.3463 & 0.9418 \\
\hline 20 & 0.6926 & 0.7866 \\
\hline 25 & 0.8658 & 0.6873 \\
\hline
\end{tabular}

Equation 60 is not dependent on the internal pressure.

Table II lists the expectation values of $t_{D}^{*} / t_{D_{0}}^{*}$ for typical variations in the temperature.

TABLE II. Expectation Value of $\mathrm{t}_{\mathrm{D}}^{*} / \mathrm{t}_{\mathrm{D}}^{*}$ 
It is apparent that temperature variations have a significant effect on lifetime. For example, if the temperature fluctuates randomly between 1500 and $1620^{\circ} \mathrm{R}$ with normal distribution, the expected lifetime is approximately one-fourth of that computed on a deterministic basis using the mean temperature. This is in qualitative agreement with the effects of random temperature on lifetime of viscoelastic structures. ${ }^{10}$

Evaluation of analogous results for brittle fracture is somewhat more complicated. Starting with the nondeterministic result comparable to that given in Eq. 52,

$$
t_{K}=\left(\frac{\sigma_{\theta_{0}}}{\sigma_{K}}\right)^{\nu}\left(B \dot{\epsilon}_{c 0} \hat{\varepsilon}\right)^{-1} \int_{1}^{\hat{\alpha}_{R}} \alpha^{2 \nu-2 n-1} d \alpha
$$

or

$$
t_{K}=\left(\frac{\sigma_{\theta_{0}}}{\sigma_{K}}\right)^{\nu}\left[2(n-\nu) B \dot{\varepsilon} \dot{\varepsilon}_{c o} \hat{\varepsilon}\right]^{-1}\left[1-\hat{\alpha}_{R}^{-2(n-\nu)}\right]
$$

thus

$$
\hat{\alpha}_{R}^{-2(n-\nu)}=1-2(n-\nu) B \dot{\varepsilon}_{C 0}\left(\frac{\sigma_{K}}{\sigma_{\theta_{0}}}\right)^{\nu} t_{K} \hat{\epsilon}
$$

Rewriting Eq. 63 as

$$
\hat{\alpha}_{\mathrm{R}}^{-2 \mathrm{n}}=(1-\mathrm{g} \hat{\varepsilon})^{\mathrm{n} /(\mathrm{n}-\nu)},
$$

where

$$
g=2(n-\nu) B \dot{\epsilon}_{c o}\left(\frac{\sigma_{K}}{\sigma_{\theta_{0}}}\right)^{\nu} t_{K}
$$

and noting Eq. 57 implies that, at failure,

$$
l-\hat{\alpha}_{K}^{-2 n}=2 n B \dot{\epsilon}_{c 0} \int_{0}^{t_{K}^{*}} \hat{\varepsilon}(\xi) d \xi
$$

Eqs. 64 and 65 may be combined to give

$$
1-(i-g \hat{\varepsilon})^{n /(n-\nu)}=2 n B \dot{\varepsilon} \operatorname{co} \int_{0}^{t}{ }^{*} \hat{\varepsilon}(\xi) d \xi,
$$

which yields the expectation value 


$$
1-\left\langle(1-g \hat{\varepsilon})^{n /(n-\nu)}\right\rangle=2 n B \dot{\varepsilon}_{c o}\langle\hat{\varepsilon}\rangle t_{K}^{*}
$$

or

$$
\left.\mathrm{t}_{\mathrm{K}}^{*}=\frac{1-\left\langle(1-\mathrm{g} \hat{\epsilon})^{\mathrm{n} /(\mathrm{n}-\nu)}\right\rangle}{2 \mathrm{nB \dot { \epsilon } _ { \mathrm { c } 0 } \langle \hat { \varepsilon } \rangle}}\right\}
$$

Finally, on dividing Eq. 67 by the deterministic result given by Eq. 55,

$$
\frac{t_{K}^{*}}{t_{K_{0}}^{*}}=\frac{1-\left\langle(1-g \hat{\varepsilon})^{n /(n-\nu)}\right\rangle}{\left[1-(1-g)^{n /(n-\nu)}\right]_{i j \hat{\varepsilon}\rangle}}
$$

Equation 68 for brittle failure differs from the ductile case in two respects: (1) It is dependent on the pressure $p$, and (2) since there is zero probability that $\hat{\varepsilon}>\mathrm{g}^{-1}$, the lognormal density function for $\hat{\varepsilon}$ is replaced with a truncated lognormal density function. Thus,

$$
f(\epsilon)=\left(\Omega \sqrt{2 \pi} \sigma_{\tau} \epsilon\right)^{-1} \exp \left[-(\ln \epsilon)^{2}\left(2 \sigma_{\tau}^{2}\right)^{-1}\right]\left[U(\epsilon)-U\left(\varepsilon-g^{-1}\right)\right],
$$

where the normalization function is

$$
\Omega=\frac{1}{2}+\operatorname{erf}\left\{\left[\ln \left(\mathrm{g}^{-1}\right)\right] \sigma_{\tau}^{-1}\right\}
$$

and the error functionerf $(x)$ is defined as

$$
\operatorname{erf}(x) \equiv \frac{1}{\sqrt{2 \pi}} \int_{0}^{x} e^{-y^{2} / 2} d y
$$

The expectation value of $\hat{\varepsilon}$ is given by

$$
\langle\hat{\epsilon}\rangle=H \Omega^{-1} \exp \left(\sigma_{\tau}^{2} / 2\right),
$$

where

$$
\mathrm{H}^{\prime}=\frac{1}{2}+\operatorname{erf}\left[\frac{\ln \left(\mathrm{g}^{-1}\right)-\sigma_{\tau}^{2}}{\sigma_{\tau}}\right]
$$

Again, as a specific example, consider a Type 304 stainless steel tube. Let $\sigma_{\mathrm{K}}=12,300 \mathrm{psi}$, the stress causing creep rupture in a uniaxial creep rupture test in $10^{5} \mathrm{hr}$ (see ASME Code Case 1331-5), and let $v / \mathrm{n}=0.7$ as suggested by Kachanov. ${ }^{11}$ Under these conditions, Eq. 68. may be evaluated in a straightforward manner for particular values of $\mathrm{p}$ and $\sigma_{\tau}$. Typical results are listed in Table III. 
TABLE III. Expectation Value of $t_{\mathrm{K}}^{*} / \mathrm{t}_{\mathrm{K}_{0}}^{*}$

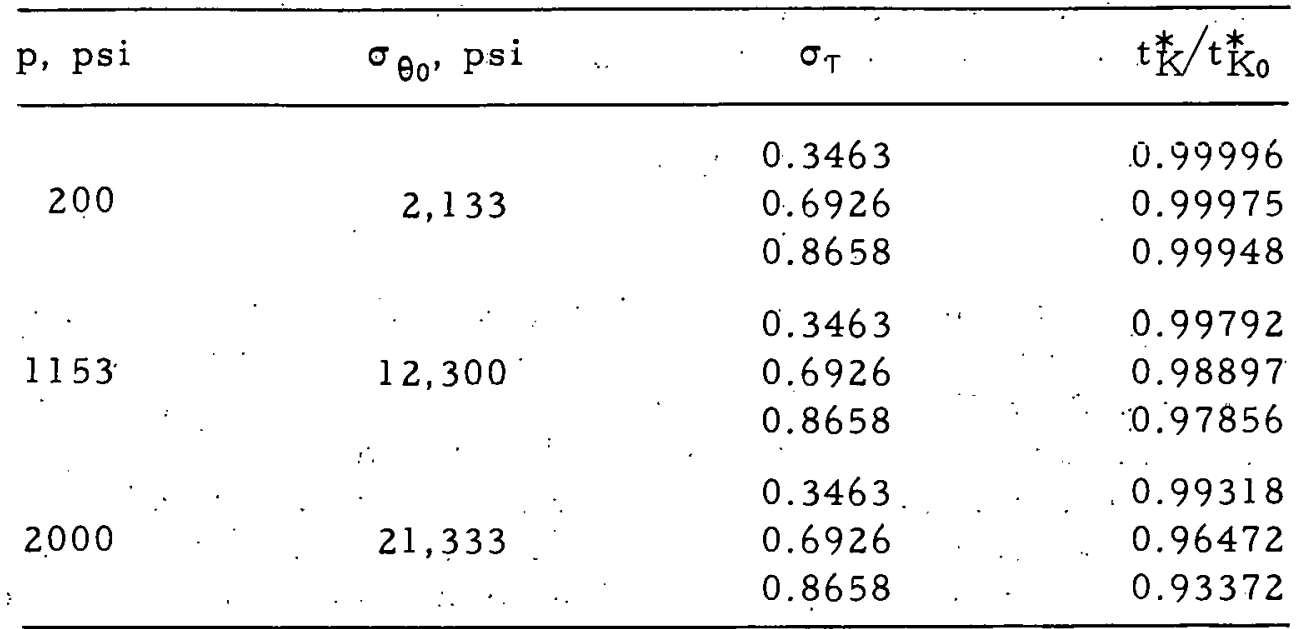

Examination of the foregoing results reveals that the time to brittle failure exhibits a relatively minor sensitivity to variations in temperature. The sensitivity increases slightly with pressure, but is not particularly significant with respect to the uncertainty involved in the physical model assumptions. This observation is in qualitative agreement with experiment. For example, Oding ${ }^{12}$ gives results on rupture strength of a particular alloy for cylindrical specimens tested both at constant temperatures of 800 and $850^{\circ} \mathrm{C}$, and cycled over the ranges $700-800-700$ and $700-850-700^{\circ} \mathrm{C}$. The rupture strength in the cyclic tests was equal to or slightly greater than that observed in the constant-temperature tests conducted at the maximum cycle temperature.

\section{EFFECTS OF RANDOMSPATIAL VARIATIONS IN TEMPERATURE ON CREEP PREDICTIONS}

In previous sections, considering plane strain problems for thin tubes made it possible to treat temperature as a function of time only and thus simplify the analysis. However, in many reactor components it is necessary to determine the creep behavior of thick sections; therefore, the assumption or random temperature variations requires a study of the temperature process as a function of both space and time.

To assess some of the difficulties associated with such spatial variations, several sample problems were considered. Due to the mathematical complexities involved in adequately treating end conditions, finite cylinders were excluded. Instead, the analysis of an infinite, thick-walled tube was outlined. Initially, it was hoped that a further simplification would result if only irradiation-induced creep was considered, since, based on current theoretical and experimental evidence, it is reasonable to as sume that strain is a linear function of stress for this creep mechanism. Unfortunately, this linear stress dependence is of minor importance when compared with the additional difficulties resulting from inclusion of the description of volume change associated with irradiation-induced creep. 
In the uniaxial case and at temperatures below those for which thermal creep is significant, the following equation is typical of the form used in describing irradiation-induced creep strain: ${ }^{13,14}$

$$
\epsilon_{\mathrm{ir} r}=\widetilde{\mathrm{A}} \frac{\sigma}{\mathrm{E}}\left[1-\exp \left(-\frac{\varphi \mathrm{t}}{\widetilde{\mathrm{B}}}\right)\right]+\widetilde{\mathrm{C}} \sigma^{\mathrm{n}} \cdot \mathrm{t},
$$

where $\mathscr{\sim}$ is the integrated fast neutron flux $(>0.1 \mathrm{MeV}), t$ is irradiation time, and $\widetilde{A}, \widetilde{B}$, and $\widetilde{C}$ are temperature-dependent constants. Based on current theoretical models and available experimental results, the irradiation creep exponent $\mathrm{n}$ is near unity for low stress levels. In what follows, it will be assumed that $n$. Also, since the transient aspects of irradiation-induced creep in stainless steels saturate at relatively low fluence $\left(\varphi t \sim 10^{21} \mathrm{n} \mathrm{cm}^{-2}\right)$, the first term in Eq. 71 will be neglected. The remaining steady-state term has been attributed to vacancy cascade nucleation and subsequent collapse into dislocation loops. This cannot be considered a constant volume process; hence, generalization of Eq. 71 to multiaxial stress states cannot follow the conventional formulation in terms of deviatoric components of the stress tensor. Some attempts have been made to convert equations such as Eq. 71 into expressions in terms of effective stress and effective strain; however, these are based on rather limited experimental evidence and involve further assumptions concerning the stress dependence of irradiation-induced isotropic swelling. For example, Gilbert and Straalsund ${ }^{15}$ established a simple proportionality between the ratio of irradiation-induced effective strain to effective stress and the ratio of strain to stress in uniaxial data (where the data also contain effects of swelling). This allowed the steady-state irradiation-induced creep to be expressed in the form

$$
\epsilon_{\mathrm{e}}=\mathrm{d}_{1} \sigma_{\mathrm{e}} \varphi \mathrm{t}
$$

where $d_{1}$ is some suitable temperature-dependent constant.

Since irradiation-induced creep is not a constant-volume process, it is reasonable to as sume (as in Ref. 15) that

$$
\dot{\varepsilon}_{i j}=\gamma \sigma_{i j}+\xi_{s} \delta_{i j}
$$

where $Y$ and $\xi$ are experimentally determined functions independent of the stress state

$$
s=\frac{1}{3}\left(\sigma_{r}+\sigma_{\theta}+\sigma_{z}\right)
$$

and $\delta_{i j}$ is the Kronecker delta. Here, it will be assumed that $\xi=\ell \gamma$, where $\ell$ is some proportionality constant.*

*Gilbert and Straalsund used limited data for Type 304 stainless steel to fix $\ell=9$. 
Consistency between Eqs. 72 and 73 requires that

$$
\mathrm{d}_{1}=\gamma\left(1+\frac{\ell}{3}\right)
$$

thus,

$$
\dot{\varepsilon}_{i j}=\frac{d_{1} \varphi}{(1+\ell / 3)}\left(\sigma_{i j}+\ell_{s} \delta_{i j}\right) \equiv d_{2}\left(\sigma_{i j}+l_{s} \delta_{i j}\right)
$$

McElroy et al ${ }^{14}$ assumed that the function analogous to $d_{1}$ was a function of the temperature $T$ and the neutron spectrum. Since exact results for the spectral dependence are not available, only the temperature dependence will be included. Data presented by McElroy show that the temperature dependence of irradiation-induced creep can be fitted with a simple exponential. From this, the final form considered for the constitutive equation becomes

$$
\dot{\varepsilon}_{i j}=d_{3} \exp (-K T)\left(\sigma_{i j}+\ell_{s} \delta_{i j}\right)
$$

where $d_{3}$ is an appropriate flux-dependent parameter, and $K$ is a known constant.

In the deterministic case, the temperature field in a thick cylinder having. inner and outer radii $a$ and $b$, respectively, is

$$
T=\ln \mathbf{r}+\beta
$$

where

$$
\alpha:=\frac{T_{b}-T_{a}}{\ln (b / a)} ; \beta=\frac{T_{a} \ln b-T_{b} \ln a}{\ln (b / a)}
$$

and $T_{a}$ and $T_{b}$ are the inner- and outer-surface temperatures. If it ${ }^{\prime} s$ as sumed that $T_{a}$ and $T_{b}$ are normal random variables $\hat{T}_{a}$ and $-\hat{T}_{b}$, with means $\overline{\mathrm{T}}_{\mathrm{a}}$ and $\overline{\mathrm{T}}_{\mathrm{b}}$ and variances $\sigma_{\mathrm{T}_{\mathrm{a}}}^{2}$ and $\sigma_{\mathrm{T}}^{2}$, the corresponding first-order density functions are then

$$
f\left(T_{a}\right)=\left[\sqrt{2 \pi} \sigma_{T_{a}}\right]^{-1} \exp \left[-\left(T_{a}-\bar{T}_{a}\right)^{2}\left(2 \sigma_{T_{a}}^{2}\right)^{\div 1}\right]
$$

and

$$
\left.f\left(\mathrm{~T}_{\mathrm{b}}\right)=\left[\sqrt{2 \pi} \sigma_{\mathrm{T}_{\mathrm{b}}}\right]^{-1} \exp \left[-\left(\ddot{\mathrm{T}}_{\mathrm{b}}-\overline{\mathrm{T}}_{\mathrm{b}}\right)^{2} \cdot\left(2 \sigma_{\mathrm{T}_{\mathrm{b}}}^{2}\right)^{-\mathrm{I}}\right]\right\}
$$

It is further assumed that the joint density function of $\hat{\mathrm{T}}_{a}$ and $\hat{\mathrm{T}}_{\mathrm{b}}$ is bivariate normal and is given by 


$$
\begin{aligned}
f\left(T_{a}, T_{b}\right)= & {\left[2 \pi \sigma_{T_{a}} \sigma_{T_{b}}\left(1-\rho^{2}\right)^{1 / 2}\right]^{-1} \exp \left\{-\left[2\left(1-\rho^{2}\right)\right]^{-1}\left[\frac{\left(T_{a}-\overline{\mathrm{T}}_{a}\right)^{2}}{\sigma_{T_{a}}^{2}}\right.\right.} \\
& \left.\left.-\frac{2 \rho\left(T_{a}-\overline{\mathrm{T}}_{a}\right)\left(T_{b}-\bar{T}_{b}\right)}{\sigma_{T_{a}} \sigma_{T_{b}}}+\frac{\left(T_{b}-\bar{T}_{b}\right)^{2}}{\sigma_{T}^{2}}\right]\right\}
\end{aligned}
$$

where. $\rho$ is the correlation coefficient. Linear functions of normal random variables remain normally distributed, and if two random variables a re jointly normal, then two functions of these two random variables are also jointly normal. The form of $\alpha$ and $\beta$ ensures that $\hat{\alpha}$ and $\hat{\beta}$ are jointly normal. It is easily shown that, for $\hat{\alpha}$,

$$
\bar{\alpha}=\langle\hat{\alpha}\rangle=\frac{\overline{\mathrm{T}}_{\mathrm{a}}-\overline{\mathrm{T}}_{\mathrm{b}}}{\ln (\mathrm{b} / \mathrm{a})}
$$

and

$$
\left.\sigma_{\alpha}^{2}=\left\langle\hat{\alpha}^{2}\right\rangle-\langle\hat{\alpha}\rangle^{2}=[\ln (\mathrm{b} / \mathrm{a})]^{-2}\left(\sigma_{\mathrm{T}_{\mathrm{b}}}^{2}-2 \rho \sigma_{\mathrm{T}_{\mathrm{a}}} \sigma_{\mathrm{T}_{\mathrm{b}}}+\sigma_{\mathrm{T}_{\mathrm{a}}}^{2}\right)\right\}
$$

and, for $\hat{\beta}$,

$$
\bar{\beta}=\frac{\bar{T}_{a} \ln b-\bar{T}_{b} \ln a}{\ln (b / a)}
$$

and

$$
\left.\sigma_{\beta}^{2}=[\ln (b / a)]^{-2}\left[\sigma_{T_{a}}^{2}(\ln b)^{2}-2 \rho \sigma_{T_{a}} \sigma_{T_{b}} \ln b \ln a+\sigma_{\mathrm{T}_{b}}^{2}(\ln a)^{2}\right]\right]
$$

that is, $\hat{\alpha}$ and $\hat{\hat{\beta}}$ are normal with means and variances as above. The joint density function is

$$
\begin{aligned}
f(\alpha ; \beta)= & {\left[2 \pi \sigma_{\alpha \sigma_{\beta}}\left(1-\rho_{\alpha \beta}^{2}\right)^{1 / 2}\right]^{-1} \exp \left\{-\left[2\left(1-\rho_{\alpha \beta}^{2}\right)\right]^{-1}\left[\frac{(\alpha-\bar{\alpha})^{2}}{\sigma_{\alpha}^{2}}\right.\right.} \\
& \left.\left.-\frac{2 \rho_{\alpha \hat{\beta}}(\alpha-\bar{\alpha})(\beta-\bar{\beta})}{\sigma_{\alpha} \sigma_{\beta}}+\frac{(\beta-\bar{\beta})^{2}}{\sigma_{\beta}^{2}}\right]\right\}
\end{aligned}
$$

where the correlation coefficient is 


$$
\begin{aligned}
\rho_{\alpha \beta} & =\frac{\langle(\hat{\alpha}-\bar{\alpha})(\hat{\beta}-\bar{\beta})\rangle}{\sigma_{\alpha} \sigma_{\beta}} \\
& =\frac{\rho \sigma_{\mathrm{T}_{\mathrm{a}}} \sigma_{\mathrm{T}_{\mathrm{b}}}(\ln \mathrm{a}+\ln \mathrm{b})-\left(\sigma_{\mathrm{T}}^{2} \ln \mathrm{a}+\sigma_{\mathrm{T}_{\mathrm{a}}}^{2} \ln \mathrm{b}\right)}{\left\{\left(\sigma_{\mathrm{T}_{\mathrm{b}}}^{2}-2 \rho \sigma_{\mathrm{T}_{\mathrm{a}}} \sigma_{\mathrm{T}_{\mathrm{b}}}+\sigma_{\mathrm{T}}^{2}\right)\left[\sigma_{\mathrm{T}}^{2}(\ln \mathrm{b})^{2}-2 \rho \sigma_{\mathrm{T}} \sigma_{\mathrm{T}_{\mathrm{b}}} \ln \mathrm{a} \ln \mathrm{b}+\sigma_{\mathrm{T}}^{2}(\ln \mathrm{a})^{2}\right]\right\}^{1 / 2}} .
\end{aligned}
$$

Since

$$
\hat{T}=\hat{\alpha} \ln r+\hat{\beta} \text {. }
$$

$\hat{\mathrm{T}}(\mathrm{r})$ is a normal process, and its first-order density function, mean, and variance may be computed from the above expressions:

$$
\begin{aligned}
f(T ; r) & =\left(2 \pi \sigma_{T}\right)^{-1} \exp \left[-\frac{(T-\bar{T})^{2}}{2 \sigma_{T}^{2}}\right] \\
\bar{T} & =\bar{\alpha} \ln r+\bar{\beta}
\end{aligned}
$$

and

$$
\sigma_{T}^{2}=\sigma_{\beta}^{2}+2 \rho_{\alpha \beta} \sigma_{\alpha} \sigma_{\beta} \ln \mathbf{r}+\sigma_{\alpha}^{2} \cdot(\ln \cdot r)^{2}
$$

In the special case where $\hat{\alpha} \equiv 0$, i.e., where the temperature is a random variable, $\hat{\mathrm{T}}=\hat{\beta}$, it is possible to show that the stresses are deterministic. The radial creep velocity $u$ can be shown to be given by

$$
\frac{\hat{\mathrm{u}}}{\mathrm{u}_{0}}=\exp [K(\bar{\beta}-\hat{\beta})]
$$

where $u_{0}$ is the nominal value (the value at $\hat{T}=\bar{T}$ ). Define

$$
\hat{\tau} \equiv K(\bar{\beta}-\hat{\beta})
$$

thus,

$$
\begin{aligned}
& \langle\hat{\tau}\rangle=0, \\
& \sigma_{\tau}^{2}=K^{2} \sigma_{\beta}^{2},
\end{aligned}
$$

and $\hat{\tau}$ is normal with mean and variance above. Since, from Ref. 1 ,

$$
\frac{\hat{\mathrm{u}}}{\mathrm{u}_{0}}=e^{\hat{\tau}}
$$


has a lognormal density function, it immediately follows that

$$
\begin{aligned}
& \left\langle\left(\frac{\hat{\mathrm{u}}}{\mathrm{u}_{0}}\right)^{\mathrm{n}}\right\rangle=\exp \left(\mathrm{n}^{2} \mathrm{~K}^{2} \sigma_{\beta}^{2} / 2\right), \\
& \left\langle\frac{\hat{\mathrm{u}}}{\mathrm{u}_{0}}\right\rangle=\exp \left(\frac{\mathrm{K}^{2} \sigma_{\hat{\beta}}^{2}}{2}\right)>1, \\
& \sigma_{\mathrm{u} / \mathrm{u}_{0}}^{2}=\exp \left(\mathrm{K}^{2} \sigma_{\beta}^{2}\right)\left[\exp \left(\mathrm{K}^{2} \sigma_{\beta}^{2}\right)-1\right]>\mathrm{K}^{2} \sigma_{\beta}^{2},
\end{aligned}
$$

and

$$
\operatorname{MAX}\left\{\frac{\hat{\mathrm{u}}}{\mathrm{u}_{0}}\right\}=\exp \left(-\mathrm{K}^{2} \sigma_{\beta}^{2}\right) \ll 1
$$

In the general case, when $\hat{\alpha} \neq 0$, the statistical properties of the stresses and other quantities of interest can be obtained only by numerical means. Introducing a suitable stress-function formulation makes it possible to obtain expressions for the stresses in a form somewhat similar to that occurring in the deterministic case; however, this formalism is of use only in numerical studies, since it involves exponents which are themselves random functions. Since the constitutive equation, Eq. 76, on which this development rests is based on scant experimental evidence, it seems unreasonable to pursue the solution of this class of problems to the point where it would be necessary to treat surh difficult numerical evaluations. Some indication of the uncertainty surrounding the formulation of constitutive descriptions of irradiation-induced creep can be gained by examining the various expressions in Ref. 16. It is immediately obvious that even the general trend of temperature dependence has not been established, nor has it been established that such a dependence exists.

For the above reasons, it is concluded that a study of the effects of spatial randomness in temperature on creep deformation cannot be profitably based on a "case study" using irradiation-induced creep. Simplifications that result from the linear stress dependence are more than outweighed by a lack of adequate theoretical and experimental descriptions of the physical process. In particular, the lack of conservation of volume during irradiation-induced creep and the lack of extensive experimental evidence concerning this phenomenon preclude a rational three-dimensional formulation of appropriate constitutive equations.

\section{SUMMARY AND CONCLUSIONS}

The problems considered in the previous sections have concentrated on the effect of random temperature on various aspects of creep of cylindrical shells. Although quantitative results are strictly applicable only to this 
geometry and hold only for specific parameters used in the examples, certain qualitative features. form a basis for more general conclusions.

For steady creep of a thin tube, a random temperature field was shown to result in an almost deterministic stress state. At the same time, predictions of the deformation rate were sensitive to temperature variations, increases in the variance of the temperature producing an increase in the variance of the deformation rate. If the latter is true in a general sense, it could have considerable impact on computations needed to satisfy design criteria. For example, if a design satisfies both the deterministic stress criteria and the strain limits. that exist in elevated-temperature rules, and if both are near their maximum allowable values, any actual temperature fluctuations could result in.violation of the strain limits while the stresses remain within the allowable range. Based on this consideration, designers should not approach the limit of allowable strains unless they have reliable temperature information. On the other hand, they should be able to approach the allowed stress. levels, even when unsure of temperature variations about given nominal values.

For the most part, general conclusions on the effect of random temperatures on creep rupture are somewhat obscured by uncertainties relating to the mathematical model. However, based on the simple model used in Sec. III, it is reasonable to conclude that any randomness in the temperature can be reflected only in a prediction of a decrease in the time to failure. The results indicate that this decrease is negligible for brittle fracture, even for a. very large variance of temperature. Qualitatively, this holds over a wide range of stress:levels in the case considered.

Attempts to gain insight into the effect of random spatial variations in temperature, using the special case of irradiation-induced creep, were not successful. The simplicity of the relationship between strain and stress was more than offset by the lack of data and uncertainty about the correct form of the constitutive relationship. Although the analytical problem proved to be tractable, it was not possible to use this to obtain any conclusive numerical results.

From the above remarks, it appears that the greatest potential for extending this initial study lies in the area of creep deformation of specific structures, rather than in pursuit of more specialized topics such as irradiation-induced creep. Of particular interest is the effect of random temperature variations on creep-buckling predictions, since design restrictions and existing standards associated with this mode of failure are severe and involve large factors of safety. Any study that explores the sensitivity or predicted times to failure would aid the early stages of design by allowing a. rational assessment of the applicability of such factors to cases in which definite information on temperature fields is unavailable. 


\section{APPENDIX}

Deterministic Calculations Using. Söderquist's Creep-damage Model

Söderquist' has modified the Rabotnov and Kachanov creep and damage relations ${ }^{6}$ through the use of a simple phenomenological model. Assuming the temperature is deterministic and constant, the basic equations are

$$
\dot{\varepsilon}=\dot{\varepsilon}_{\mathrm{C} 0} \sigma_{\mathrm{C}}^{-\mathrm{n}}\left(\frac{\mathrm{Q}}{\mathrm{A}}\right)^{\mathrm{n}}(1-\mathrm{D})^{-\mathrm{n}} .
$$

and

$$
\dot{D}=C\left(\frac{Q}{A}\right)^{\nu}(1-D)^{-\nu}
$$

where $D$ is a measure of damage due to creep $(0 \leq D \leq 1), Q$ is a constant load, $A$ is the specimen cross-sectional area, and $C$ and $v$ are constants in the damage.law

$$
\stackrel{\circ}{\mathrm{D}}=\mathrm{C} \sigma_{\mathrm{a}}^{\nu}
$$

where $\sigma_{a}$ is the stress acting over the undamaged area. This is essentially a simplification of the Rabotnov law in that the number of empirical constants a re reduced.

For the thin-tube problem, Eqs. A.1 and A.2 become

$$
\dot{\varepsilon}_{\theta}=\dot{\varepsilon}_{\mathrm{c} \theta}\left(\frac{\sqrt{3}}{2}\right)^{\mathrm{n}+1}\left(\frac{\sigma_{\theta}}{\sigma_{\mathrm{c}}}\right)^{\mathrm{n}} \cdot\left(1-D_{\theta}\right)^{-\mathrm{n}}
$$

and

$$
\dot{D}_{\theta}=C \sigma_{\theta}^{\nu}\left(1-D_{\theta}\right)^{-\nu}
$$

Substitution of Eqs. 45 and 46 . into Eq. A.4 gives

$$
\alpha^{-(2 n+1)} \dot{\alpha}=B \dot{\varepsilon}_{c 0}\left(1-D_{\theta}\right)^{-n} \text {, }
$$

which is analogous to Eq. 47 used in the simplified treatment. Dividing. Eq. A.6 - by $D_{\theta}$, as given in:Eq. A.5, and using Eq. 46 then gives.

$$
\frac{1}{2(\nu-n)} \frac{d}{d t}\left[\alpha^{2(\nu-n)}\right]=\dot{\varepsilon}_{c 0} B C^{-1} \sigma_{\theta_{0}}^{-\nu}\left[\frac{-1}{1-(n-\nu)}\right] \frac{d}{d t}\left(1-D_{\theta}\right)^{1-(n-\nu)}
$$

Equation A.7, together with the initial condition $\alpha=1$ for $D_{\theta}=0$, then yields 


$$
\left(1-D_{\theta}\right)^{-n}=\left\{i-g\left[1-\alpha^{-2(n-\nu)}\right]\right\}^{-\dot{n} /[1-(n-\nu)]},
$$

where

$$
g=\frac{1-(n-\nu)}{2(n-\nu)} \frac{C \sigma_{\theta_{0}}^{\nu}}{\dot{\varepsilon}_{c_{0} B} B}
$$

Substitution of Eq. A. 8 into Eq. A.6 reduces the equation for $\alpha$ to the form

$$
\dot{\alpha}=\mathrm{a} \alpha^{\mathrm{m}}\left(\mathrm{b}+\mathrm{g} \alpha^{-\mathrm{k}}\right)^{\mathrm{q}},
$$

where

$$
\begin{aligned}
& \mathrm{a}=\mathrm{B} \dot{\epsilon}_{\mathrm{c} 0}, \mathrm{~m}=2 \mathrm{n}+1, \quad \mathrm{~b}=1-\mathrm{g}, \\
& \mathrm{q}=\frac{-\mathrm{n}}{\mathrm{i}-(\mathrm{n}-\nu)}, \text { and } \mathrm{k}=2(\mathrm{n}-\nu) .
\end{aligned}
$$

Denoting by $\alpha_{R}$ the value of $\alpha$ at the time of brittle failure, use of the failure criteria: Eq. 51 , together with Eq. A.9, gives

$$
t_{K}=\frac{1}{a}\left(\frac{\sigma_{\theta_{0}}}{\sigma_{K}}\right)^{\nu} \int_{1}^{\alpha_{R}} \frac{\alpha^{2 \nu} d \alpha}{\alpha^{m}\left(b+g \alpha^{-k}\right)^{q}} .
$$

Also, since $t_{K}$ is defined as that particular value of the time to rupture for which the stress remains constant, it can be shown that

$$
\begin{aligned}
& \mathrm{C} \sigma_{K^{t_{K}}}^{\nu}=\frac{1}{\nu+1} ; \text { hence, } \\
& \mathrm{g}=\frac{1+\nu-\mathrm{n}}{2(\mathrm{n}-\nu)(1+\nu)} \frac{\left(\sigma_{\left.\theta_{0} / \sigma_{K}\right)^{\nu}}\right.}{\dot{\epsilon}_{\mathrm{co}} t_{K} \mathrm{~B}}
\end{aligned}
$$

From direct integration of Eq. A.9,

$$
t_{\text {so }}^{*}=\frac{1}{a} \int_{1}^{\alpha_{R}} \frac{d \alpha}{\alpha^{m}\left(b+g \alpha^{-k}\right)^{q}} .
$$

Equations A.10 and A.1 1 together form a parametric representation of the time to brittle rupture.

To compare Eqs. A. 10 and A. 11 to the simpler result given by Eq. 55, a specific numerical example is considered. Let $\sigma_{\mathrm{K}}$ equal the stress causing rupture in $10^{5} \mathrm{hr}$ in uniaxial creep rupture test. For Type 304 stainless steel at $1100^{\circ} \mathrm{F}$, this would give $\sigma_{\mathrm{K}}=12,300$ psi (see ASME Code Case 1331-5). 
Kachanov ${ }^{11}$ gives, as the limits on $\nu$, the expression $0.62<v / n<1$, and suggests 0.7 as a representative mean value. Table IV compares the numerical results obtained from Eqs. A.10, A.11, and 55 for various values of internal pressures.

TABLE IV. Comparison between Calculated Values of $\mathrm{t}_{\mathrm{K}_{0}}$ and $\mathrm{t}_{\text {so }}^{*}$

\begin{tabular}{rrrr}
\hline & & \multicolumn{2}{c}{ Time tö Rupture, hr } \\
\cline { 3 - 4 } p, psi & $\sigma_{\theta_{0}}, \mathrm{psi}$ & $\mathrm{Eq}_{\mathrm{K} .}^{*}: 55$ & Eqs. $\Lambda .10_{\mathrm{so}}^{*}$ and A.11 \\
\hline 200 & 2,133 & $6.907 \times 10^{8}$ & $6.905 \times 10^{8}$ \\
1153 & 12,300 & $9.89: 5 \times 10^{4}$ & $9.743 \times 10^{4}$ \\
2000 & 21,333 & $5.998 \times 10^{3}$ & $5.709 \times 10^{3}$ \\
\hline
\end{tabular}

From these results it is noted that the modified theory shows a reduction in the time to rupture; however, the difference is too slight to justify the increase in computational complexity that would result from this theory. 


\section{REFERENCES}

1. F. A. Cozzarelli and W. N. Huang, Effect of Random Material Parameters on Nonlinear. Steady Creep Solutions, Int. J. Solids Struct. $7(11)$, 1177-1494 (1971).

2. J. Aitchison and J. A. C. Brown, The Lognormal Distribution, Cambridge University Press, New York (1957).

3. A Parametric Study to Establish Design Curves and to Evaluate Design Rules for Rachetting, Teledyne Materials Research Technical Report No, F. -1.414 (1.972).

4. N. J. Hoff. The Necking and Rupture of Rods Subjected to Constant Tensile Loads, J. Appl. Mech. 20(1), 105-108 (Mar 1953).

5. L. M. Kachanov, On Failure Time Under Conditions of Creep, Izv. Akad. Nauk SSSR Otd. Tehn. Nauk No. 8, pp. 26-31. (Aug 1958).

6. F. K. G. Odqvist, Mathematic Theory of Creep and Creep Rupture, Oxford University Press, New York, Chaps. 3, 10, and.11 (1966).

7. E. L. Robinson, Effect of Temperature Variation on the Long-Time Rupture Strength of Steels, Trans. ASME 74(5), 777-781 (July 1952).

8. F. K. G. Odqvist and J. Hult, Some Aspects of Creep Rupture, Ark. Fys. $19(26), 379-382$ (1961).

9. B. Söderquist, Some Aspects of Creep and Creep Rupture, Acta Polytech. Scand. Phys., including Nucleonics Series No. 58 (1968).

10. H. Parkus, "On the Lifetime of Viscoelastic Structures in a Random Temperature Field," Recent Progress in Applied Mechanics--Folke Odquist. Volume, John Wiley \& Sons, New York, pp. 391-397 (1967).

11. L. M. Kachanov, "Rupture Time Under Creep Conditions," Problems of Continuum Mechanics, Contributions in Honor of 70 th Birthday of N.I. Muskhelishvili (Feb 16, 1961).

12. I. A. Oding, Creep and Stress Relaxation in Metals, Oliver \& Boyd, Edinburgh, Scotland (1965).

13. A. Boltax, P. Murray, and A. Biancheria, Fast Reactor Fuel Performance Model-Development, Nuc1. App1. 9(3), 326-337 (Sept 1970).

14. W. N. McElroy, R. E. Dahl, Jr., and E. R. Gllbert, Neutron EnergyDependent Damage Function for Anatysis of Austenitic Steel Creep Data, Nucl. Eng. Design 14, 319-331 (1970).

15. E. R. Gilbert and J. L. Straalsund, A Relationship for Non-Conservative Volume Creep Under Different States of Stress, Nucl. Eng. Design 12, 421-424 (1970).

16. R. C. Schmitt and T. R. Bump, "LMFBR Core-restraint Design," Reactor Development Program Progress Report: August 1972, ANL-RDP-8, pp. 6.12-6.15 (Oct 10, 197.2). 